\title{
Aortic valve replacement with the Björk-Shiley tilting disc valve prosthesis
}

\author{
Viking Olov Björk \\ From the Thoracic Surgical Clinic, Karolinska Sjukhuset, Stockholm, Sweden
}

The Björk-Shiley tilting disc valve (Björk, 1969) has now been used in more than 120 cases, $9 \mathrm{I}$ in the aorta and $3 \mathrm{I}$ in the mitral area (Björk, 1970a). The 9I aortic valve replacements had a primary mortality of 8.8 per cent. There were 2 severe complications necessitating reoperation, one paravalvular leakage, and one aortic incisional aneurysm. The first 47 cases, followed up from 6 to 17 months, have been carefully investigated with aortography and left-heart catheterization at rest and during exercise (Björk, 1970b). The systolic peak pressure gradient, especially during exercise, was significantly lower over the Björk-Shiley valve $(16 \mathrm{~mm}$. $\mathrm{Hg}$ ) than over the StarrEdwards valve $(4 \mathrm{I} \mathrm{mm} . \mathrm{Hg}$ ) and the $\mathrm{Kay}-$ Shiley valve $(38 \mathrm{~mm}$. $\mathrm{Hg})$. As the resulting blood trauma was decreased the remaining haptoglobin in plasma was twice as high in the patients with Björk-Shiley valves as in those with Starr-Edwards and Kay-Shiley valves.

After more than Io years' clinical experience with artificial heart valves, two factors have been found most important for the result: the durability of the valve, and the pressure gradient over the prosthesis.

After 8 years' excellent function with the Starr-Edwards ball valve prosthesis I was at first hesitant about trying other artificial valves. It was, however, the unacceptable high pressure gradient over the smaller ball valves that necessitated the introduction of a new tilting disc valve prosthesis for aortic valve replacement. Seven out of 9 cases with aortic valve replacement with the No. 8 StarrEdwards ball valve prosthesis died, and resting gradients up to $70 \mathrm{~mm}$. $\mathrm{Hg}$ were encountered. The results with the Smeloff-Cutter ball valves and Kay-Shiley disc valves were also unsatisfactory in narrow aortic roots, where a Dacron outflow prosthesis often had to be utilized to enlarge the clearance between the disc and the aortic wall.

Complications with calcification and shrinkage of cusps fashioned from the patient's own pericardium or fascia for aortic valve replacement in my own experience
(Björk and Hultquist, 1964), and the report of only $I$ in 3 good long-term results of homograft replacement (Barratt-Boyes et al., I969), have convinced me that the best durability may be achieved with artificial valves.

Apart from durability, the lowest possible gradient is the only other most important feature of an artificial valve. To decrease the gradient a valve without a central occluder must be used. The first such valve I used was that constructed by Wada-Cutter. After 8 months, in cases with concomitant sinus of Valsalva or ascending aortic aneurysm, the metal shoulder, hitting the same area at each heart beat, caused a groove in the Teflon disc and resulted in valvular insufficiency with the Wada-Cutter valves in 2 of I I patients within one year.

\section{The aortic tilting disc valve}

To eliminate the drawback in construction of the Wada valve, a new central flow tilting disc design with a free floating and rotating Delrin disc has been introduced (Fig. I). The free floating disc is uniquely suspended in a Stellite cage with a vertical sewing ring of thin Teflon. The Delrin disc tilts open to $60^{\circ}$ and provides central flow. (The mitral version opens only to $50^{\circ}$, as the velocity of blood flow is much less through the mitral valve.) The pivot point of the disc shifts towards the centre as the disc closes, thereby reducing closure impact velocity. The disc has an extremely low mass inertia: its weight in a 23 $\mathrm{mm}$. valve is only $0.34 \mathrm{~g}$. The disc does not overlap the ring, but fits within the orifice area. It can usually rotate one turn in 100-200 heart cycles.

\section{Flow tests}

In a tilting disc valve prosthesis the ratio of total orifice area to tissue diameter is significantly increased to permit laminated flow. The low gradient of the disc prosthesis and the fact that the disc does not hit the ring during diastole have reduced blood trauma to a minimum. When small particles of gold leaf 


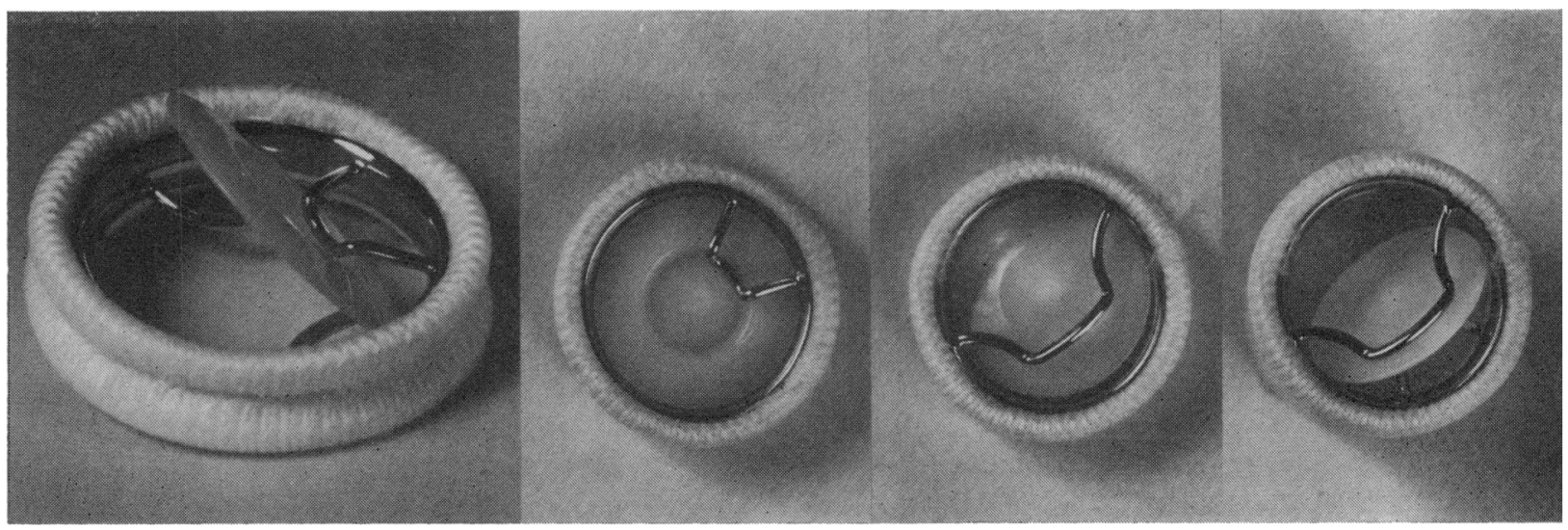

FIG. I (a) The Björk-Shiley aortic valve prosthesis with a free floating disc tilted open to $60^{\circ}$ in a Stellite cage. The outflow cage leg in the central excavation of the disc will keep the rotating Delrin disc in place. (b) The valve viewed from the aortic side in a closed position.

(c) The valve viewed from the left ventricuiar side in a closed position. (d) The valve viewed from the left ventricular side in an open position.

are suspended in the fluid in the pulse duplicator a laminated flow will be demonstrated that has never been observed with other valves tested (Fig. 2). Around a ball valve prosthesis a turbulent flow is demonstrated. In pulse duplicator studies with an aortic flow of 150 $300 \mathrm{ml} . / \mathrm{sec}$. the gradient of the tilting disc valve is significantly lower than that over other commonly used and tested valves such as Starr-Edwards, Kay-Shiley, Wada-Cutter, and Smeloff-Cutter models. The comparison was made with prostheses of the same external diameter of $23 \mathrm{~mm}$., a stroke volume of 70 $\mathrm{ml}$., and a pulse frequency of 70 at an aortic pressure of $125 / 75 \mathrm{~mm} . \mathrm{Hg}$, and resulted in a gradient of only $2.5 \mathrm{~mm}$. Hg with the BjörkShiley tilting disc valve prosthesis (Björk and Olin, 1970) (Fig. 3).

\section{Durability tests}

The durability of the tilting disc valve prosthesis was tested by accelerated cycling at

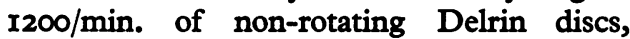
utilizing a test fluid of glycerin and water with a specific gravity of I roo. In these tests the discs were tethered to prevent rotation and to magnify the wear effect in localized areas. In pulse duplicator studies at a pulse rate of $50-150 \mathrm{cycles} / \mathrm{min}$. the disc rotated about one revolution every 200 pulses. In accelerated cycling no rotation of the disc was encountered and a wear depth of $0.15 \mathrm{~mm}$. was found after 5 years. From this study the in vivo durability is estimated to be approximately 30 years for a non-rotating $23 \mathrm{~mm}$. tilting disc valve prosthesis in the aortic area, and 20 years for the large $29 \mathrm{~mm}$. valve without rotation of the disc.
Two patients have been reoperated after 9 and 7 months and no visible wear has been detected on the discs. However, a microphotograph of the Delrin disc, implanted in a patient for 7 months and removed for inspection at reoperation, showed an indentation of 0.0005 inch, which should correspond to a functional life of more than 100 years. The Delrin was found to be 7 times more resistant to wear than

FIG. 2 Photographic visualization of the laminated flow in the Björk-Shiley aortic valve, using a shutter speed of $1 / 20$ sec., during injection of an illuminated suspension of small particles of gold leaf (Björk and Olin, 1970).

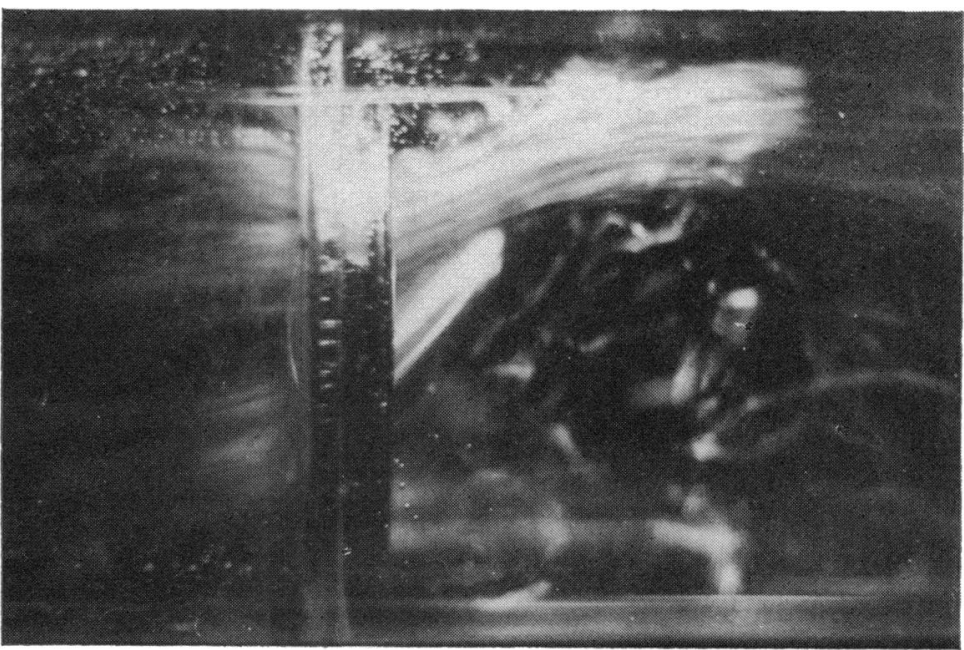




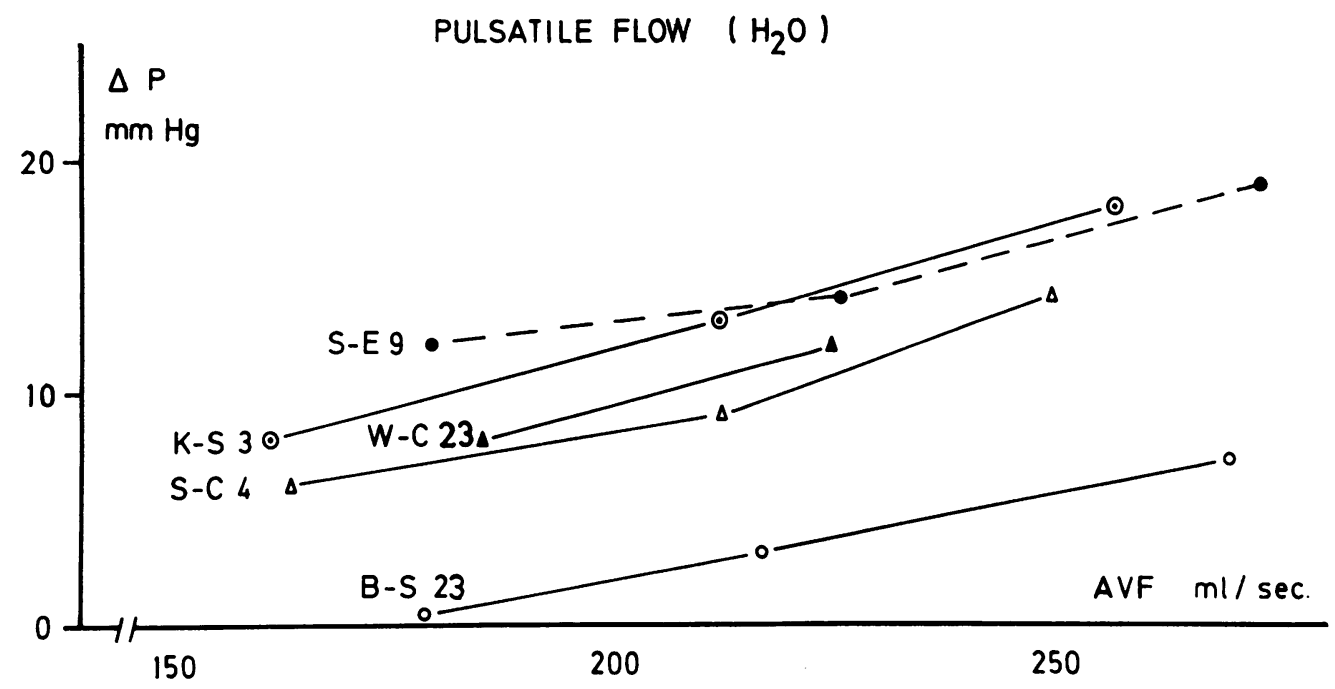

FIG. 3 Mean pressure difference in $\mathrm{mm}$. $\mathrm{Hg}$ in relation to aortic valve flow $(A V F)$ in ml./sec. obtained in the pulse duplicator studies of valves with identical tissue diameter, Starr-Edwards (S-E 9), Kay-Shiley (K-S 3), Wada-Cutter (W-C 23), Smeloff-Cutter (S-C 4), and BjörkShiley $(B-S$ 23). The gradient was significantly lower in the Björk-Shiley valve compared with the other valves tested (Björk and Olin, 1970).

Teflon and twice as resistant as Halon during these wear tests.

\section{Operative procedure}

All patients have been operated upon with the AGA heart-lung machine with the Björk disc oxygenator and automatic blood level control, using both left and right coronary artery perfusion at $30^{\circ} \mathrm{C}$. The coronary artery perfusion is not started until the valves have been removed. The sizer should pass easily into the left ventricle, as it is important not to select an unnecessarily large valve. Approximately 30 isolated Tycron sutures are placed through the lower portion of the sewing ring, but in the commissures they are placed in the upper portion to avoid extra tension and cutting through (Fig. 4). When all sutures are tied the inner ring and disc can be rotated and oriented so that the movement of the disc is free. Usually the downward going portion of the disc is oriented toward the non-coronary sinus or the commissure between the right and non-coronary cusp. At the end of operation a negligible gradient is found over the valve.

Anticoagulant treatment is started on the third postoperative day.

\section{Material}

Altogether 9I patients have been operated on for aortic valvular disease, using the tilting disc valve prosthesis. All patients experienced one or more of the three cardinal symptoms of anginal pain, syncopal attacks, and dyspnoea. There were 64 cases with calcific aortic stenosis with a gradient of more than $50 \mathrm{~mm}$. $\mathrm{Hg}$, with or without some degree of insufficiency. There were 27 cases of aortic insuffici-

FIG. 4 Diagram demonstrating the location of isolated Tycron sutures through the valvular rim and the lower portion of the suture ring. In the commissures the sutures are placed in the upper portion of the ring.

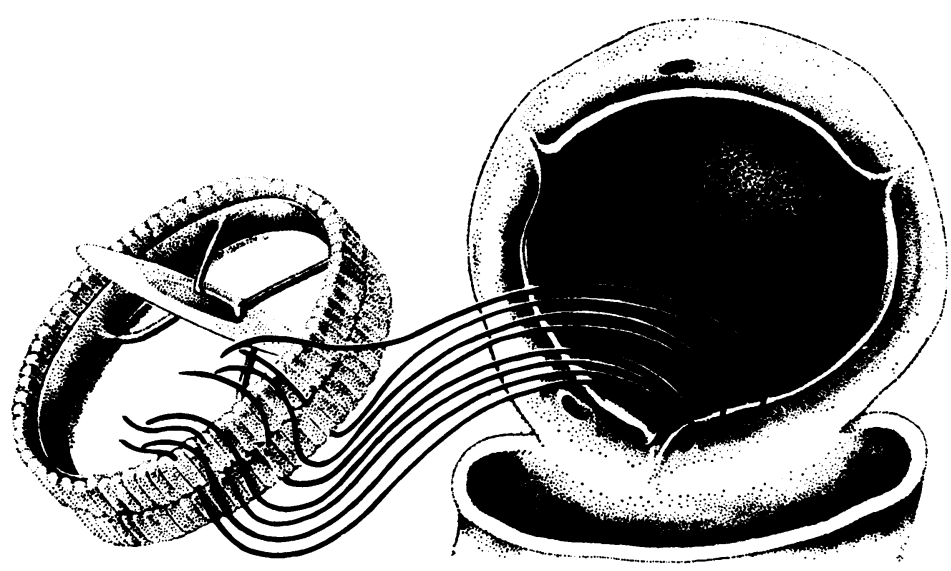



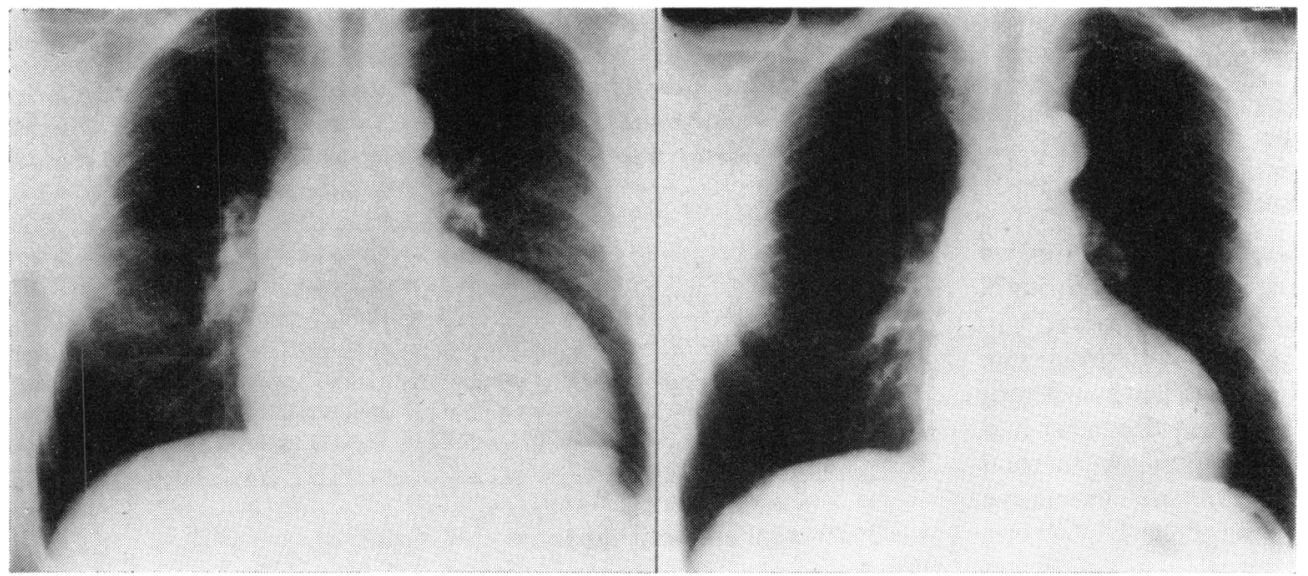

FIG. $5 X$-ray of a 6I-year-old man with combined calcific aortic stenosis and insufficiency demonstrating the decrease in total heart size from $2200 \mathrm{ml}$. to $1300 \mathrm{ml}$. in 6 months after the insertion of a $27 \mathrm{~mm}$. Björk-Shiley aortic tilting disc valve prosthesis. The peak systolic pressure difference was II $\mathrm{mm}$. $\mathrm{Hg}$ at rest (cardiac output $7 \cdot 7 \mathrm{l} . / \mathrm{min}$.) and $20 \mathrm{~mm}$. $\mathrm{Hg}$ during exercise (cardiac output $15 \cdot 1$ l./min.).

ency, and I9 patients had concomitant procedures: one patient had an ascending aortic aneurysm (Marfan's syndrome) resected and grafted, one had an obstructive cardiomyopathy resected, 9 patients also had mitral valve replacement, 7 had mitral commissurotomy, and one patient had a ventricular septal defect closed with a patch.

\section{Results of aortic valve replacement}

Operative mortality In the 91 cases of aortic valve replacement there were 8 deaths $(8.8 \%)$. The fatal outcome had no direct relation to the performance of the valve prosthesis in any of these cases. Six deaths were due to myocardial failure $(0,1,1,2,5$, and 5 months postoperatively), and 2 patients died from sepsis ( 3 weeks and 2 months postoperatively).

Complications Two cases of embolism occurred in connexion with the operative procedure of removal of calcific aortic valves, resulting in paraplegia. One is alive and confined to a wheelchair, the other died in myocardial failure after an unsatisfactory outcome of a concomitant mitral commissurotomy. In one case an incisional aneurysm was detected by aortography at the follow-up investigation 7 months after operation. One case had a paravalvular insufficiency, necessitating reoperation with closure 9 months after valve implantation.

Follow-up The remaining 83 patients are alive and well $I$ to $I 7$ months after operation, except one with paraplegia, mostly sitting in a wheelchair but able to walk with the aid of two sticks. Thirty-four patients were followed for more than one year. The first 47 cases have been carefully investigated with aortography, transseptal catheterization, and determination of the pressure difference over the aortic prosthesis at rest and during exercise.

Subjective improvement Of the 47 patients investigated, all but 2 considered themselves in better condition. Thirty were free of symptoms and in excellent condition; 15 were much better, but 4 of them still had continued angina pectoris, one complained of shortness of breath, one had an attack of dizziness, and one had a total block. The two unimproved patients were reoperated, one for a paravalvular leakage and the other for an aneurysm in the ascending aortic incision.

Heart size The average total heart size before surgery was II $40 \mathrm{ml}$., which diminished in 6 months to $920 \mathrm{ml}$. The corresponding relative heart size diminished from $630 \mathrm{ml} . / \mathrm{m}^{2}{ }^{2}$ to $520 \mathrm{ml} . / \mathrm{m}^{2}$ during the 6 months following operation. The most pronounced decrease in heart size was found in a 6I-year-old man with combined calcific aortic stenosis and insufficiency, where the total size diminished from $2200 \mathrm{ml}$. to $1300 \mathrm{ml}$. in 6 months (Fig. 5).

Working capacity At the follow-up investigation the working capacity was:

$\begin{array}{rrrr}1200 \mathrm{kpm} . / \mathrm{min} . & \text { in } & 3 \text { patients } \\ 800 & \text { " } & \text { I2 } & \text { " } \\ 600 & \text { " } & 9 & \text { " } \\ 400 & \text { I2 } & \text { " } \\ \text { less than } & 400 \mathrm{kpm} . / \mathrm{min} . & 5 & \text { " }\end{array}$


Regurgitation Regurgitation at the followup aortography was classified:

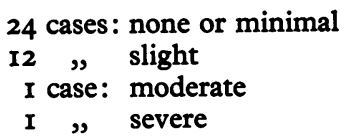

In the cases with slight regurgitation on aortography I or 2 sutures had cut through, causing $2-3 \mathrm{~mm}$. regurgitant jet, usually in one commissure. In the case with moderate insufficiency on aortography, this was without haemodynamic significance and the heart had decreased from $1030 \mathrm{ml}$. to $670 \mathrm{ml}$. in total and from $630 \mathrm{ml} . / \mathrm{m}^{2}$ to $390 \mathrm{ml} . / \mathrm{m}^{2}$. in relative size. The case with severe insufficiency had one $3 \mathrm{~mm}$. and one $10 \mathrm{~mm}$. suture insufficiency at two commissures and was reoperated. Nine cases did not undergo aortography. Eight of them had no diastolic murmur, while one had a slight murmur.

Pressure The systolic peak pressure difference over the aortic tilting disc valves was significantly lower than with Starr-Edwards and Kay-Shiley prostheses. The increase of pressure difference during exercise is very slight over the Björk-Shiley tilting disc valves, especially when compared with other valves with central occluders (see Table).

Plasma haptoglobin The average plasma haptoglobin value was $44 \mathrm{mg}$. per cent at the follow-up. The values of haematocrit and haemoglobin were within normal range in all patients except the one with a significant paravalvular leakage necessitating reoperation.

\section{Discussion}

The relief of symptoms following replacement with the Björk-Shiley aortic valve has been very satisfactory. Most patients are able to live normally and resume their work. All patients are anticoagulated.

At the follow-up investigation the tilting disc valve has been found to have a great haemodynamic advantage over valves with a central occluder. The peak pressure difference at rest and during exercise is significantly less over the Björk-Shiley valves as compared with the Starr-Edwards and Kay-Shiley valve prostheses (Björk, Olin, and Åstrom, 1969) (Table). The advantage is most obvious in cases with a narrow aortic root, and during exercise. Thus the average pressure increase during exercise over the Björk-Shiley aortic valve was $\mathrm{I} 6 \mathrm{~mm}$. $\mathrm{Hg}$ compared with $4 \mathrm{I} \mathrm{mm}$. $\mathrm{Hg}$ over the Starr-Edwards and $38 \mathrm{~mm} . \mathrm{Hg}$ over the Kay-Shiley valve. The ability to with-
TABLE The average peak systolic pressure difference over the Björk-Shiley aortic valve compared with values found in cases operated upon with the Starr-Edwards and Kay-Shiley valves in the aortic area

\begin{tabular}{lllllc}
\hline Valve & $\begin{array}{l}\text { No. of } \\
\text { cases }\end{array}$ & $\begin{array}{l}\text { Rest } \\
\text { gradient } \\
(\mathrm{mm} . \mathrm{Hg})\end{array}$ & Range & $\begin{array}{l}\text { Exercise } \\
\text { gradient } \\
(\mathrm{mm} . \mathrm{Hg})\end{array}$ & Range \\
\hline Björk-Shiley & $4 \mathrm{I}$ & $\mathrm{II} \cdot 8$ & $0-37$ & $\mathrm{I6}$ & $0-59$ \\
Starr-Edwards & 46 & $17 \cdot 5$ & $0-47$ & $4 \mathrm{I}$ & $0-85$ \\
Kay-Shiley & 34 & 27 & $9-6 \mathrm{I}$ & 38 & $10-1 \mathrm{co}$ \\
\hline
\end{tabular}

stand attacks of tachycardia without fall of blood pressure in the immediate postoperative period has been observed in several patients with the Björk-Shiley valve.

As the central laminated flow gives a smaller systolic peak pressure gradient, the blood trauma is decreased compared with cases having prostheses of the central occluding type. This decreased blood trauma has resulted in an average plasma haptoglobin value of 44 mg. per cent with the Björk-Shiley valves, approximately twice that found after operation with the Starr-Edwards (19 mg.\%) and the Kay-Shiley) $20 \mathrm{mg} . \%$ ) prostheses.

\section{References}

Barratt-Boyes, B. G., Roche, A. H. G., Brandt, P. W. T., Smith, J. C., and Lowe, J. B. (I969). Aortic homograft valve replacement. A long-term followup of an initial series of ror patients. Circulation, 40, 763 .

Björk, V. O. (1969). A new tilting disc valve prosthesis. Scandinavian fournal of Thoracic and Cardiovascular Surgery, 3, I.

(I970a). The central flow tilting disc valve prosthesis (Björk-Shiley) for mitral valve replacement. Scandinavian fournal of Thoracic and Cardiovascular Surgery, 4, 15 .

- (1970b). A new central flow tilting disc valve prosthesis: One year's clinical experience with $\mathrm{IO}_{3}$ patients. Fournal of Thoracic and Cardiovascular Surgery, 60, 355.

aortic valve prostheses. Fournal of Thoracic and Cardiovascular Surgery, 47, 693.

-, and Olin, C. (1970). A hydrodynamic comparison between the new tilting disc aortic valve prosthesis (Björk-Shiley) and the corresponding prostheses of Starr-Edwards, Kay-Shiley, SmeloffCutter and Wada-Cutter in the pulse duplicator. Scandinavian fournal of Thoracic and Cardiovascular Surgery, 4, 3I.

$\longrightarrow,-$, and Åstrom, H. (1969). Results of aortic valve replacement with the Kay-Shiley disc valve. Scandinavian fournal of Thoracic and Cardiovascular Surgery, 3, 93. 